\title{
Modified Cassava Starches as Potential Corrosion Inhibitors for Sustainable Development
}

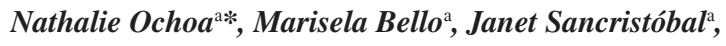 \\ Vittoria Balsamo ${ }^{\mathrm{b}}$, Alberto Albornoz ${ }^{\mathrm{c}}$, Joaquin L. Brito ${ }^{\mathrm{c}}$ \\ ${ }^{a}$ Departamento de Ciencia de los Materiales, Universidad Simón Bolívar, \\ Aptdo. 89000, Caracas, Venezuela \\ ${ }^{b}$ Nalco, Ecolab Company, Energy Services Division, 7705 Highway 90A, \\ Sugar Land, TX 77494, USA \\ 'Laboratorio de Fisicoquímica de Superficies, Centro de Química, \\ Instituto Venezolano de Investigaciones Científicas - IVIC, Altos de Pipe, \\ Carretera Panamericana, Km 11, Edo. Miranda, Venezuela
}

Received: October 18, 2012; Revised: March 28, 2013

\begin{abstract}
Activated (AS) and carboxymethylated ( $\mathrm{CMS}_{0.24}$ ) cassava starch derivatives were studied as corrosion inhibitors for carbon steel XC35 in a $200 \mathrm{mgL}^{-1} \mathrm{NaCl}$ solution. They were characterized by back titration and Fourier Transform Infrared Spectroscopy (FTIR). Electrochemical techniques were used to evaluate the inhibitive properties of starches at room temperature and the chemical composition of the protective films was determined by X-Ray Photoelectron Spectroscopy (XPS). Electrochemical measurements revealed that AS acts as mixed inhibitor, whereas $\mathrm{CMS}_{0.24}$ mainly inhibits the anodic reaction. In both cases, the protection increased with the inhibitor concentration; nevertheless, after 24 hours of immersion, the $\mathrm{CMS}_{0.24}$ loses its properties, while AS molecules still maintains them. XPS analyses show that the inhibitive films are composed of an iron oxide/hydroxide mixture in which starch molecules are incorporated. Results were explained taking into consideration the hydrophilicity and the strength of the ionic interaction of the starches with the metal surface.
\end{abstract}

Keywords: carbon steel, green corrosion inhibitors, electrochemical measurements, cassava starch

\section{Introduction}

There is currently considerable interest in developing "green" or low toxicity corrosion inhibitive formulations in response to legislation changes concerning environmental protection. Chemicals disposal, which is a common practice in corrosion and scaling treatments for "clean" water systems, such as cooling water circuits or potable water systems, is being more and more restricted and penalized. Therefore, there is a growing need to produce corrosion inhibitors that are not toxic for human beings and that have a low eutrophication level with an optimal biodegradability. Initial interest in "green inhibitors" began in the 1990s; since then, there has been an increasing research activity on the inhibitive properties of eco-friendly and harmless compounds. In this sense, some authors have reported the use of tannins, amino acids, vitamins, proteins, polymers, and phosphono compounds as corrosion and scaling inhibitors ${ }^{1-3}$ to replace toxic metal cations, phosphates, and polymers having a low biodegradability level $1^{1,4-19}$. Unfortunately, these last compounds are still used because they are effective at relatively low cost.

Starch is a renewable, biodegradable, and readily available polymer at low cost, which may be obtained from rice, corn, wheat, and cassava, among other sources. Starches are widely employed in food, paper-making, textile,

*e-mail: nochoa@usb.ve and pharmaceutical industries. It is also used as additive in cements and drilling muds in oil well ${ }^{20}$. Native starch may, however, exhibit some drawbacks that restrict its use, such as insolubility in cold water and sensitivity to shearing and low $\mathrm{pH}^{21}$. The physical and/or chemical modification of this polysaccharide may, therefore, enhance its applications range. The carboxymethylation of starch results in a modified starch (CMS) with carboxylate groups $\left(\mathrm{CH}_{2} \mathrm{COO}^{-}\right)$, which disturb the ordered structure of native starch, reduce the gelatinization temperature, increase solubility in water, and lead to higher storage stability ${ }^{22}$. The synthesis of CMS has been previously studied ${ }^{23}$, but recently, researchers have focused their investigations on the improvement of the products and synthesis paths to obtain appropriate degrees of substitution (DS) ${ }^{23-28}$.

The aim of this work is to prepare and use cassava starch derivatives as "green" inhibitors for corrosion protection of carbon steel. Cassava starch was selected as precursor for the derivatives because cassava is a woody shrub that is extensively cultivated in tropical and subtropical regions ${ }^{21}$, but it has not been as widely commercialized as, for example, corn starch. It must be noticed that up to our knowledge, only few works have been published dealing with the use of starches as protective material against corrosion ${ }^{11,29,30}$. Sugama et al. ${ }^{11}$ employed a polyorganosiloxane-grafted potato starch and an unmodified potato starch as coating 
to afford protection of aluminum. On the other hand, Abd El Halemm et al. ${ }^{29}$ employed a soluble starch, among other compounds, to improve the pitting corrosion resistance of a carbon steel; nevertheless, these authors did not specify the starch they used and the type and amount of functional groups present in the starch. Other work that can be mentioned is the publication of Rosliza and Wan $\mathrm{Nik}^{30}$ in 2009, who reported that cassava starch could improve the corrosion resistance of an aluminum alloy in seawater. It should be mentioned that in most of the works dealing with natural products as corrosion inhibitors, tests have been performed under acid conditions, and significantly less work has been published about the use of natural compounds in neutral-alkaline solutions ${ }^{1,2,8,10,29}$. More recently, we have reported that modified cassava starches exhibit corrosion inhibitive properties for carbon steel in a solution that simulates the chemical composition of tap water ${ }^{31-33}$. In this work, electrochemical measurements and X-ray Photoelectron Spectroscopy (XPS) analysis were coupled to investigate parameters such as type of modification, inhibitor concentration and time of immersion, with the aim of understanding the inhibition mechanism of these species.

\section{Experimental}

\subsection{Preparation and characterization of modified starches}

The biopolymers used as inhibitors were an activated cassava starch (AS) and a carboxymethylated cassava starch (CMS); their chemical structures are shown in Figure 1. They were prepared from native cassava starch, provided by Agroindustriales Mandioca S.A., following the procedure described in previous works ${ }^{31-33}$. The success of the modification process was determined by means of Fourier Transform Infrared Spectroscopy (FTIR), using a Nicolet Magna IR 760 spectrometer with a resolution of $4 \mathrm{~cm}^{-1}$, to obtain the spectra from films casted onto $\mathrm{AgBr}$ discs. The CMS degree of substitution was determined by back titration, with the experimental procedure described in previous investigations ${ }^{32,33}$.

\subsection{Corrosion experiments}

The corrosive medium was a $200 \mathrm{mgL}^{-1}$ sodium chloride solution, maintained at $25^{\circ} \mathrm{C}$ in contact with air. This

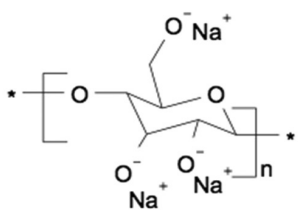

AS

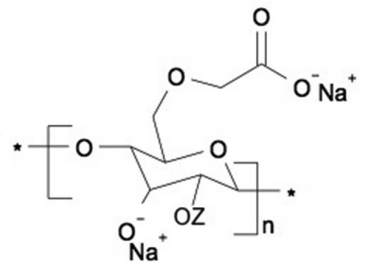

CMS
Figure 1. Chemical structures of activated (AS) and carboxymethylated starch (CMS), where $\mathrm{Z}$ indicates a $\mathrm{Na}^{+}$cation or a carboxymethyl group. medium is a simplification of the composition of natural waters, which has been often employed ${ }^{32,34-36}$ to study corrosion and inhibition due to its low conductivity, fairly high corrosivity, and because it is easily reproducible at a laboratory scale. Modified cassava starches (AS and CMS) were tested as inhibitors at different concentrations: 200, 400 and $600 \mathrm{mgL}^{-1}$. The $\mathrm{pH}$ of the solution containing the inhibitors was of $10.0 \pm 0.5$. For the blank solution, the $\mathrm{pH}$ was modified to 10.0 by adding sodium hydroxide. It should be pointed out that the addition of the starch molecules produces an increase in the solution viscosity ${ }^{27}$, leading to a reduction of the relative oxygen solubility ${ }^{37}$, which in this case is the corrosive agent. Even though the addition of the starch modifies the solution viscosity, the $200 \mathrm{mgL}^{-1}$ sodium chloride solution was employed for comparison purposes because the maximum decrease of the relative oxygen solubility is of only about $7 \%{ }^{37}$ when CMS is added.

A rod of XC 35 carbon steel having a cross-sectional area of $0.79 \mathrm{~cm}^{2}$ was used as working electrode. Its nominal composition in percentage by weight is $0.35 \mathrm{C}, 0.65 \mathrm{Mn}$, $0.25 \mathrm{Si}, 0.035 \mathrm{P}, 0.035 \mathrm{~S}$, and Fe balance. The electrodes were covered by a heat-shrinkable sheath to leave only the tip of the carbon steel cylinder in contact with the solution. Before carrying the electrochemical tests, the steel samples were polished with $\mathrm{SiC}$ paper down to grade 1200. Afterwards, they were cleaned with ethanol, rinsed with distilled water, and dried with warm air.

Polarization curves and electrochemical impedance diagrams were recorded using a Gamry Potentiostat DC-105 model. These techniques were coupled with a rotating disk electrode to control mass transport phenomena. The electrode rotation rate was fixed at $1000 \mathrm{rpm}$. Experiments were performed in a standard Pyrex double wall cell. The counter-electrode was a platinum grid, and a saturated calomel electrode (SCE) was used as reference. Potentiodynamic polarization curves were obtained after 2 hours of immersion at the open circuit potential for all concentrations. Then, the working electrode was polarized continuously from the cathodic to the anodic range $(-0.950-0.150 \mathrm{~V} / \mathrm{SCE})$. Potential sweep rate was fixed at $10 \mathrm{mV} / \mathrm{min}^{38}$. The polarization curves were corrected for the ohmic drop. Electrochemical impedance measurements were carried out under potentiostatic regulation in a frequency range of $100 \mathrm{kHz}$ to $6 \mathrm{mHz}$ with eight points per decade using a $8 \mathrm{mV}$ peak-to-peak sinusoidal potential. Impedance diagrams were obtained at the corrosion potential for different inhibitor concentrations and immersion times. Electrochemical results were obtained from at least three experiments to ensure reproducibility.

\subsection{Surface analysis}

The surface chemical composition of the inhibitive layers was studied using X-ray photoelectron spectroscopy (XPS). The XPS measurements were carried out in a VG Escalab model 220i-XL. The samples to be analysed were obtained by cutting disks of about $3 \mathrm{~mm}$ of thickness from the metallic cylinder used as working electrode. They were pasted with a conductive adhesive to the steel rod to be immersed in the $200 \mathrm{mgL}^{-1} \mathrm{NaCl}$ solution containing the inhibitors. Then, the samples were maintained at 
the corrosion potential for different immersion times at $1000 \mathrm{rpm}$. After the measurements, they were removed from the solution, dried in warm air, and the disks were placed in a vacuum chamber. Once the ultra-high vacuum regime $\left(10^{-9}\right.$ Torr $)$ was reached, the specimens were irradiated with a non monochromatic $\mathrm{MgK} \alpha \mathrm{X}$-ray source of $300 \mathrm{~W}$. Measurements were carried out at a take-off angle $\theta=90^{\circ}$. The experimental resolution of the binding energy was less than $0.5 \mathrm{eV}$. After background substraction, peak deconvolution was performed using the XPSPEAK4.1 software. Binding energies were corrected for possible charging effects by referencing to the $\mathrm{C} 1 \mathrm{~s}$ at $284.5 \mathrm{eV}$ using the XPSGRAF102 software. The chemical state of iron was tested by examining the $\mathrm{Fe} 2 \mathrm{p}_{3 / 2}$ signal. The adsorption of the inhibitors on the steel surface was monitored by means of the characteristic $\mathrm{C} 1 \mathrm{~s}$ and $\mathrm{O} 1 \mathrm{~s}$ peaks.

\section{Results}

\subsection{Structural characterization of the starches}

The chemical changes of the starch were verified by FTIR. Figure 2 shows a comparison of the FTIR spectra for activated (AS) and carboxymethylated (CMS) starch. In both spectra, bands at 575,765 , and $862 \mathrm{~cm}^{-1}$ are observed and attributed to $\mathrm{C}-\mathrm{C}$ stretching and $\mathrm{C}-\mathrm{H}$ bending vibrations of the anhydroglucose unit (AGU). In the fingerprint region between 900 and $1500 \mathrm{~cm}^{-1}$, the bands located at about 933 , 1000, 1082, and $1157 \mathrm{~cm}^{-1}$ correspond to -C-O-C- bonds in the $\mathrm{AGU}^{39}$. The band at $1649 \mathrm{~cm}^{-1}$ originates from tightly bound water present in $\operatorname{starch}^{40}$, and those observed at $2929 \mathrm{~cm}^{-1}$ and $\sim 3350 \mathrm{~cm}^{-1}$ are due to the characteristic vibrations of $\mathrm{C}-\mathrm{H}$ and $-\mathrm{OH}$ bonds. In the spectrum of the CMS, two new signals are clearly appreciated at $1605 \mathrm{~cm}^{-1}$ and $1417 \mathrm{~cm}^{-1}$, which correspond to non-symmetric and symmetric stretching of carboxylate $\left(-\mathrm{COO}^{-}\right)$groups ${ }^{27,28,41}$, demonstrating the successful reaction of monochloroacetic acid with the starch backbone. At this point, it should be mentioned that in the case of AS, only alkoxy groups $\left(-\mathrm{CO}^{-}\right)$

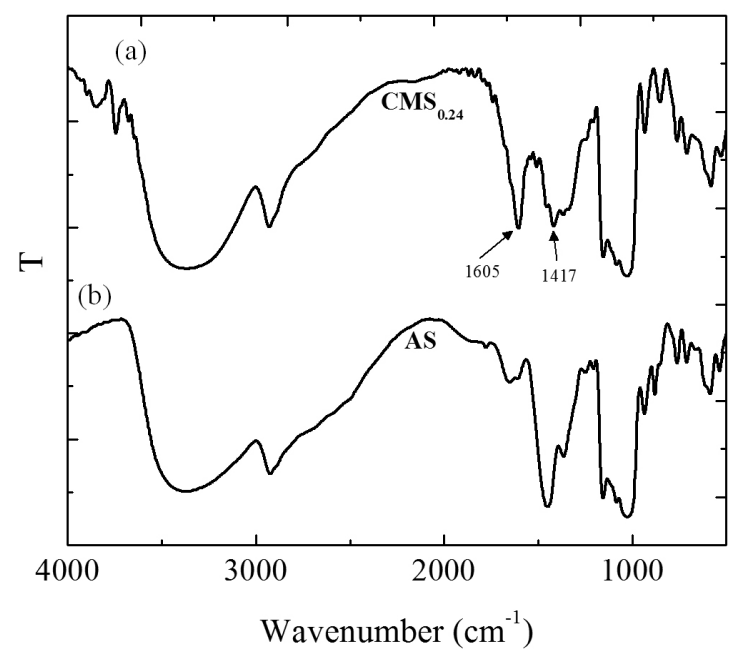

Figure 2. FTIR spectra of (a) $\mathrm{CMS}_{0.24}$ and (b) AS. are available to interact with the steel surface, whereas in the CMS, both alkoxy and carboxylate $\left(\mathrm{COO}^{-}\right)$groups are capable to be adsorbed on the metal surface. This is in agreement with our previous results, where structural characterization of modified starches was carried out by Nuclear Magnetic Resonance ${ }^{32}$.

\subsection{Effect of the concentration and modification process of starches on the corrosion inhibitive properties}

Figure 3 shows the variation of the corrosion potential, $E_{\text {corr }}$, of the carbon steel electrode as a function of the immersion time, in the presence of different concentrations of AS and $\mathrm{CMS}_{0.24}$, respectively. It is observed that the corrosion potentials in the presence of inhibitors are close to that obtained for the blank solution, whatever the inhibitor concentration. In addition, regardless of the inhibitive species, these values remain constant at around $-400 \mathrm{mV} / \mathrm{SCE}$, after approximately one hour of immersion, indicating that the electrochemical system reaches the steady state.

Potentiodynamic polarization curves obtained after two hours of immersion in the solution containing AS or $\mathrm{CMS}_{0.24}$ at different concentrations are presented in Figure 4. They are compared with the current-voltage curve obtained without inhibitor. In the presence of $\mathrm{AS}$ and $\mathrm{CMS}_{0.24}$, it may be observed that the anodic and cathodic kinetics depend on inhibitor concentration. The anodic and the cathodic branches describe the iron dissolution and the oxygen
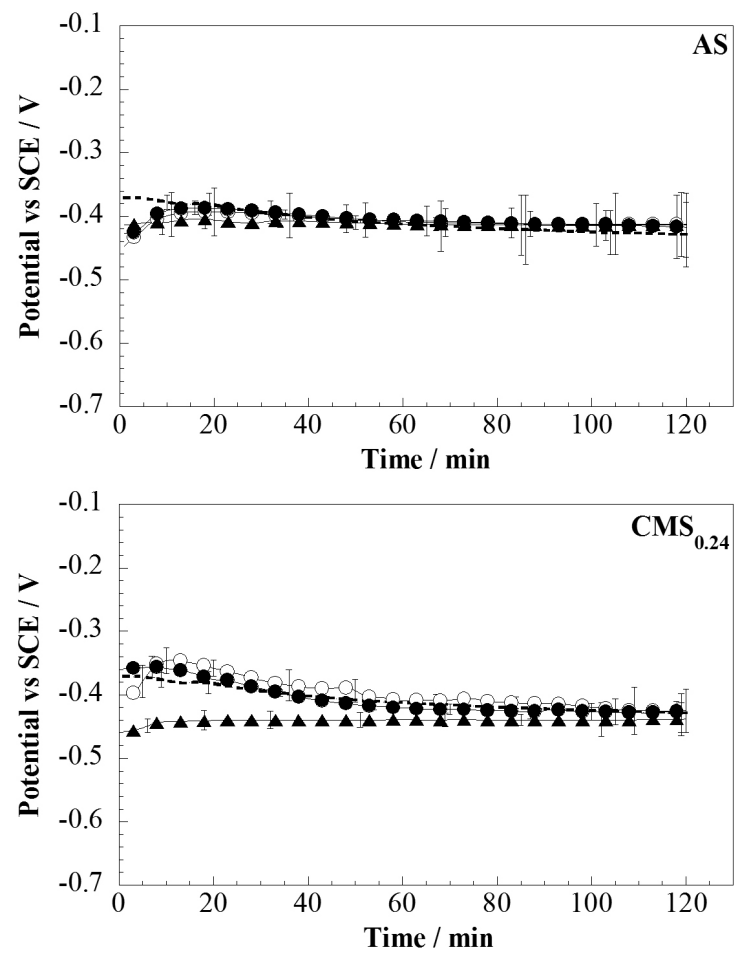

Figure 3. Corrosion potential of the carbon steel electrode as a function of immersion time in the $200 \mathrm{mgL}^{-1} \mathrm{NaCl}$ solution (---) and in the presence of inhibitors: $(\boldsymbol{\Delta}) 200 \mathrm{mgL}^{-1},(\bullet) 400 \mathrm{mgL}^{-1}$, (०) $600 \mathrm{mgL}^{-1}$. 
reduction reaction, respectively. Furthermore, the shape of the polarization curves suggests that both kinetics are under mixed control. When using AS, it is observed that in the anodic domain, the current densities are lower than for the blank solution for the whole overpotential range; for $\mathrm{CMS}_{0.24}$ it happens only at potentials near $E_{\text {corr }}$. For the lowest $\mathrm{CMS}_{0.24}$ concentration $\left(200 \mathrm{mgL}^{-1}\right)$, the anodic branch shows the active dissolution of the metal; in contrast, for AS, the anodic current density remains lower than that obtained for the blank solution. At higher inhibitor concentrations, the inhibitive effect is enhanced in the presence of both species, but the anodic current density is remarkably lower for $600 \mathrm{mgL}^{-1}$ of activated starch. In the cathodic domain, the current density only decreases for the highest AS concentration, while for 200 and $400 \mathrm{mgL}^{-1}$, cathodic currents are similar to that
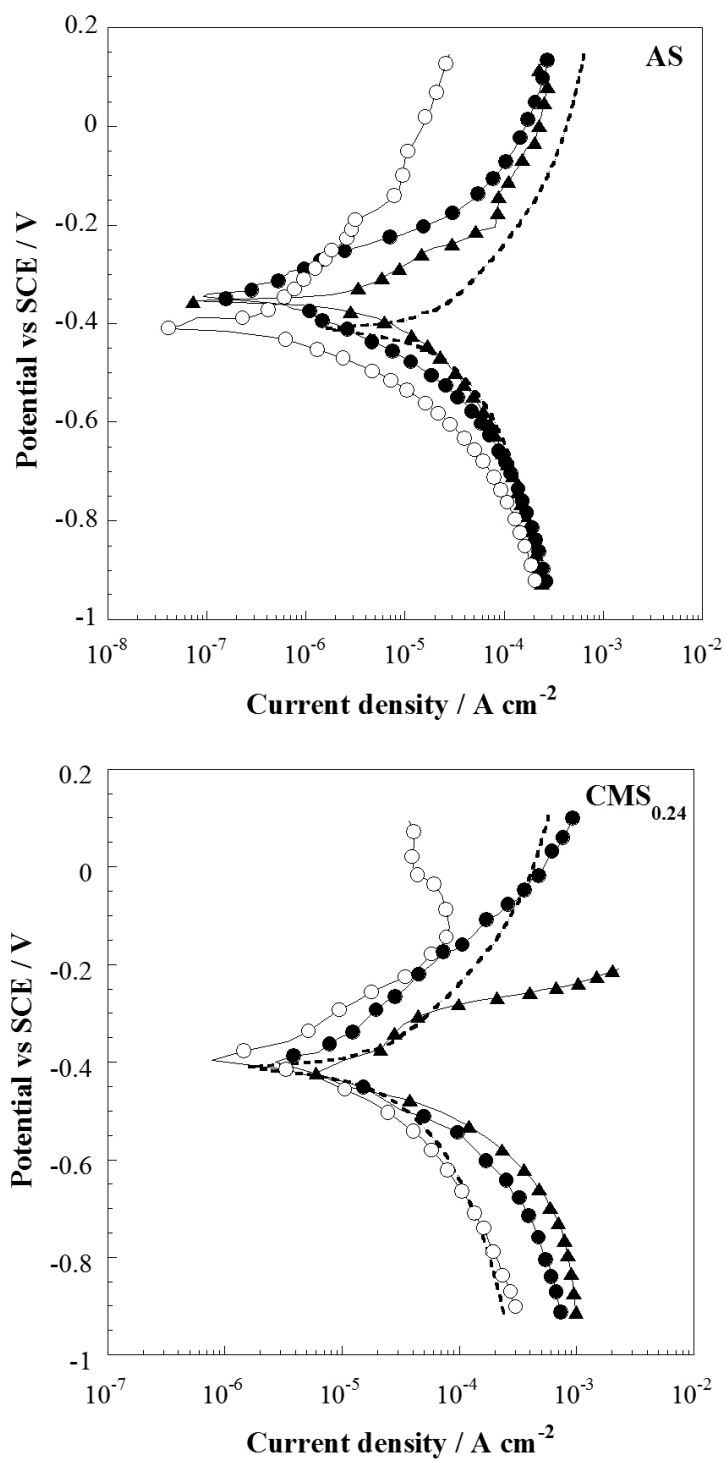

Figure 4. Polarization curves obtained for the carbon steel electrode after $2 \mathrm{~h}$ of immersion at $E_{\text {corr }}$ in the $200 \mathrm{mgL}^{-1} \mathrm{NaCl}$ solution (---) and in the presence of inhibitors: («) $200 \mathrm{mgL}^{-1},(\bullet) 400 \mathrm{mgL}^{-1}$, (०) $600 \mathrm{mgL}^{-1}$. obtained for the blank solution. This was not observed for $\mathrm{CMS}_{0.24}$ because of the higher current densities compared with the reference curve. The increase of the cathodic kinetic could be related to desorption of the macromolecules when the working electrode is negatively polarized; therefore, the oxygen reduction reaction is accelerated by the presence of bared areas on the metal surface. Results obtained from the polarization curves indicate that AS acts as mixed inhibitor, whereas $\mathrm{CMS}_{0.24}$ acts as anodic one.

Figure 5 shows the electrochemical impedance diagrams obtained at the corrosion potential, after 2 hours of immersion in the solution containing AS or $\mathrm{CMS}_{0.24}$, at different concentrations. Electrochemical parameters obtained from these diagrams are listed in Table 1. The polarization resistance values of the films formed on the electrode surfaces $(\mathrm{Rp})$ were obtained by extrapolating the impedance diagrams on the real axis and, the CPE parameters, $Q_{\text {eff }}$ and $\alpha$, were determined using the graphic method proposed by Orazem et al. ${ }^{42,43}$ in order to take into account the distribution of reactivity of the electrode surface.

It can be noted that when inhibitors are added to the corrosive solution, the impedance diagrams are larger than in the blank solution; this result accounts for the inhibitive effect of the starch molecules. The size of the impedance diagrams increases with the inhibitor concentration; however, in the presence of AS, the spectra are significantly larger than those obtained for $\mathrm{CMS}_{0.24}$ at the highest concentration. In addition, the impedance spectra are composed by a single capacitive loop for all AS concentrations, but the flattened shape of the impedance spectra suggests the presence of at least two time constants for CMS, in agreement with the $\alpha$ parameter. The increase of $\mathrm{Rp}$ and the decrease of $\mathrm{Q}_{\mathrm{eff}}$ values, particularly in the presence of AS, suggest differences in the adsorption mechanisms of these biopolymers.
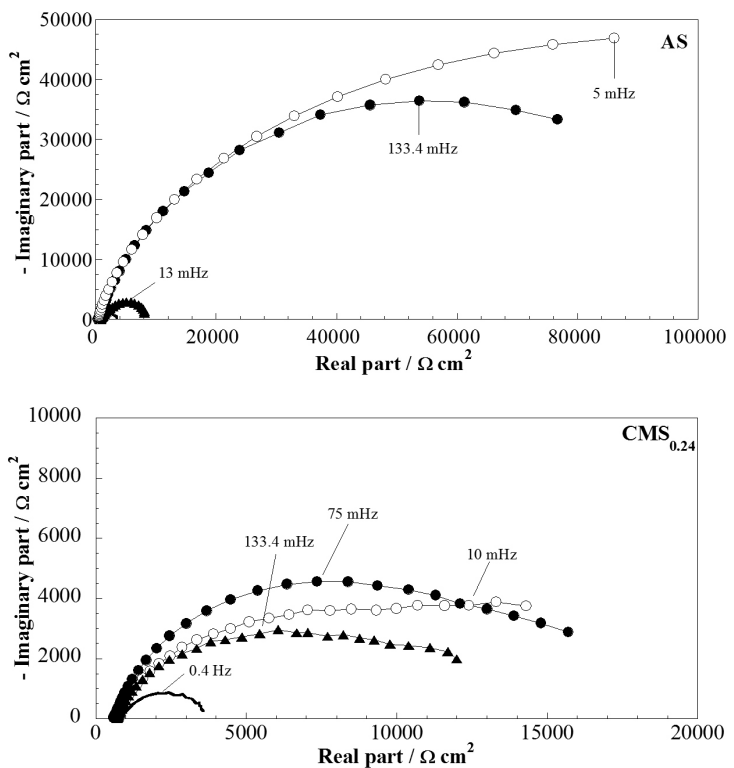

Figure 5. Electrochemical impedance diagrams obtained after $2 \mathrm{~h}$ of immersion at $E_{\text {corr }}$ in the $200 \mathrm{mgL}^{-1} \mathrm{NaCl}$ solution (---) and in the presence of inhibitors: (४) $200 \mathrm{mgL}^{-1},(\bullet) 400 \mathrm{mgL}^{-1}$, (०) $600 \mathrm{mgL}^{-1}$. 
Table 1. Characteristic parameters and inhibition efficiency obtained from the impedance diagrams presented in Figure 5.

\begin{tabular}{lccccc}
\hline & $\begin{array}{c}\text { Inhibitor concentration } \\
\left(\mathbf{m g L}^{-1}\right)\end{array}$ & $\begin{array}{c}R_{P} \\
\left(\Omega . \mathbf{c m}^{2}\right)\end{array}$ & $\begin{array}{c}Q_{\text {eff }} \\
\left(\boldsymbol{\mu} \mathbf{F} \cdot \mathbf{c m}^{-2}\right) \mathbf{s} \boldsymbol{~}^{-1}\end{array}$ & $\alpha$ & $\begin{array}{c}\varepsilon \\
(\boldsymbol{\%})\end{array}$ \\
\hline Blank & & $3900 \pm 400$ & 290 & 0.5 & - \\
\hline \multirow{3}{*}{$\mathbf{A S}$} & 200 & $8200 \pm 800$ & 215 & 0.6 & 59 \\
& 400 & $110000 \pm 8000$ & 73 & 0.8 & 97 \\
\hline \multirow{2}{*}{$\mathbf{C M S}_{0.24}$} & 600 & $175000 \pm 7000$ & 68 & 0.8 & 98 \\
& 200 & $14000 \pm 700$ & 121 & 0.7 & 77 \\
\hline
\end{tabular}

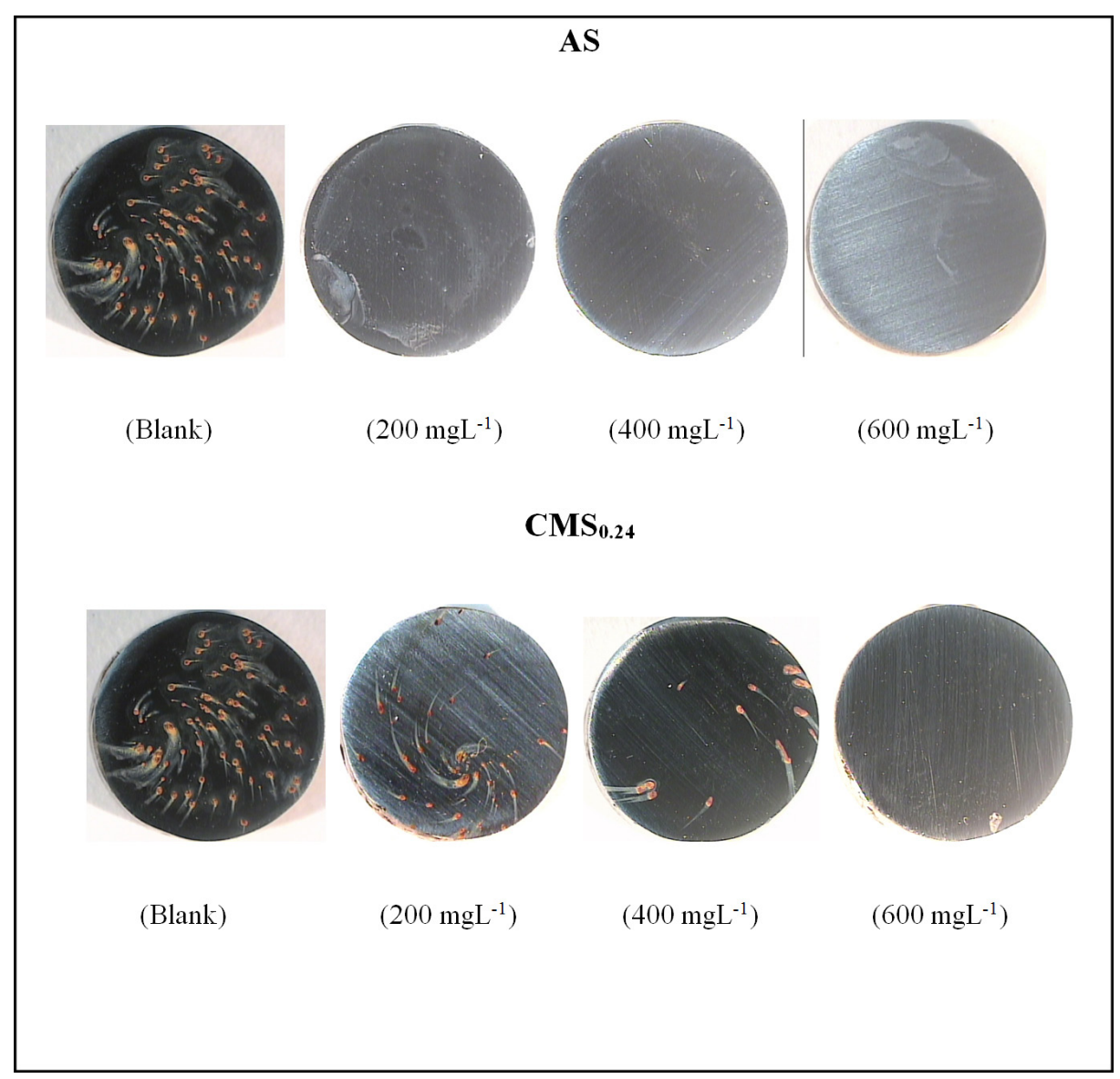

Figure 6. Pictures of the XC 35 carbon steel surfaces after $2 \mathrm{~h}$ of immersion without inhibitor (a) and in the presence of inhibitors: (b) $200 \mathrm{mgL}^{-1}$, (c) $400 \mathrm{mgL}^{-1}$, (d) $600 \mathrm{mgL}^{-1}$.

Figure 6 shows pictures of the electrode surfaces taken after two hours of immersion in the corrosive medium. It can be observed that many corrosion product spots that follow the hydrodynamic of the system are developed from pits on the metal surface. The traces of rust tend to disappear when the inhibitors are added to the sodium chloride solution. It has to be highlighted that this effect is observed with just $200 \mathrm{mgL}^{-1}$ of $\mathrm{AS}$; however, higher CMS concentrations are required in order to obtain a bright metallic surface. The images described are in accordance with the electrochemical results.

Table 1 shows the inhibition efficiency calculated according to Equation 1, where Rp and Rp' are the polarization resistance values with and without inhibitor, respectively.

$\varepsilon=\frac{R_{p}-R_{p}^{\prime}}{R_{p}} \times 100$

It may be observed that for AS, the efficiency values are as high as $98 \%$, revealing the higher effectiveness of this compound in comparison with other natural products at similar concentrations ${ }^{1-4,8-12}$. In agreement with previous results, the inhibition efficiency obtained for AS at high concentrations is greater than with $\mathrm{CMS}_{0.24}$. 
In order to determine the chemical composition of the inhibitive films, XPS analysis were carried out on the carbon steel surface after two hours of immersion in the solution containing $600 \mathrm{mgL}^{-1}$ of AS or $\mathrm{CMS}_{0.24}$. At this concentration, the highest inhibition efficiency was achieved as shown previously. Figures 7 and 8 illustrate a comparison of the X-ray photoelectron spectra of $\mathrm{Fe} 2 \mathrm{p}_{3 / 2}, \mathrm{O} 1 \mathrm{~s}$, and $\mathrm{C} 1 \mathrm{~s}$ obtained from the inhibitive films formed on the steel surface, and from AS and $\mathrm{CMS}_{0.24}$ powders, respectively.

From Figure $7 \mathrm{a}$ (when AS was employed), the Fe $2 \mathrm{p}_{3 / 2}$ spectrum is essentially composed by a broad signal, whose deconvolution results in three peaks at 712.5, 710, and $707 \mathrm{eV}$. The peak located at $707 \mathrm{eV}$ is attributed to metallic iron, while those at $710 \mathrm{eV}$ and $712.5 \mathrm{eV}$ may be assigned to iron oxide/hydroxide species ${ }^{44-47}$. Similar signals are also apparent in the deconvoluted $2 \mathrm{p}_{1 / 2}$ envelope centered around $725 \mathrm{eV}$ (not shown). The O1s peak is composed of three peaks at 530.3, 531.9, and $532.8 \mathrm{eV}$; the first two peaks correspond to the binding energy of the $\mathrm{O}^{2-}$ and $\mathrm{OH}^{-}$ions, in agreement with the presence of the iron oxide/hydroxide layer as detected in the $\mathrm{Fe} 2 \mathrm{p}_{3 / 2}$ spectrum. The signals at $531.9 \mathrm{eV}$ and $532.8 \mathrm{eV}$ also corresponds to oxygen in the C-O, O-C-O, and C-O species, which are present in the inhibitor ${ }^{48,49}$. Their presence, especially in the latter ones, demonstrates that the activated starch molecules are adsorbed on the steel surface. This is in agreement with the signals in the $\mathrm{C} 1 \mathrm{~s}$ region, where peaks due to $\mathrm{C}-\mathrm{H}$ and $\mathrm{C}-\mathrm{C}$ bonds at $283.5 \mathrm{eV}$ and $284.7 \mathrm{eV}$, and to $\mathrm{O}-\mathrm{C}-\mathrm{O}$ and $\mathrm{C}-\mathrm{O}$ bonds at $287 \mathrm{eV}$ and $289.1 \mathrm{eV}$ were obtained ${ }^{50-51}$. Indeed, these peaks are also observed in the XPS spectra of the

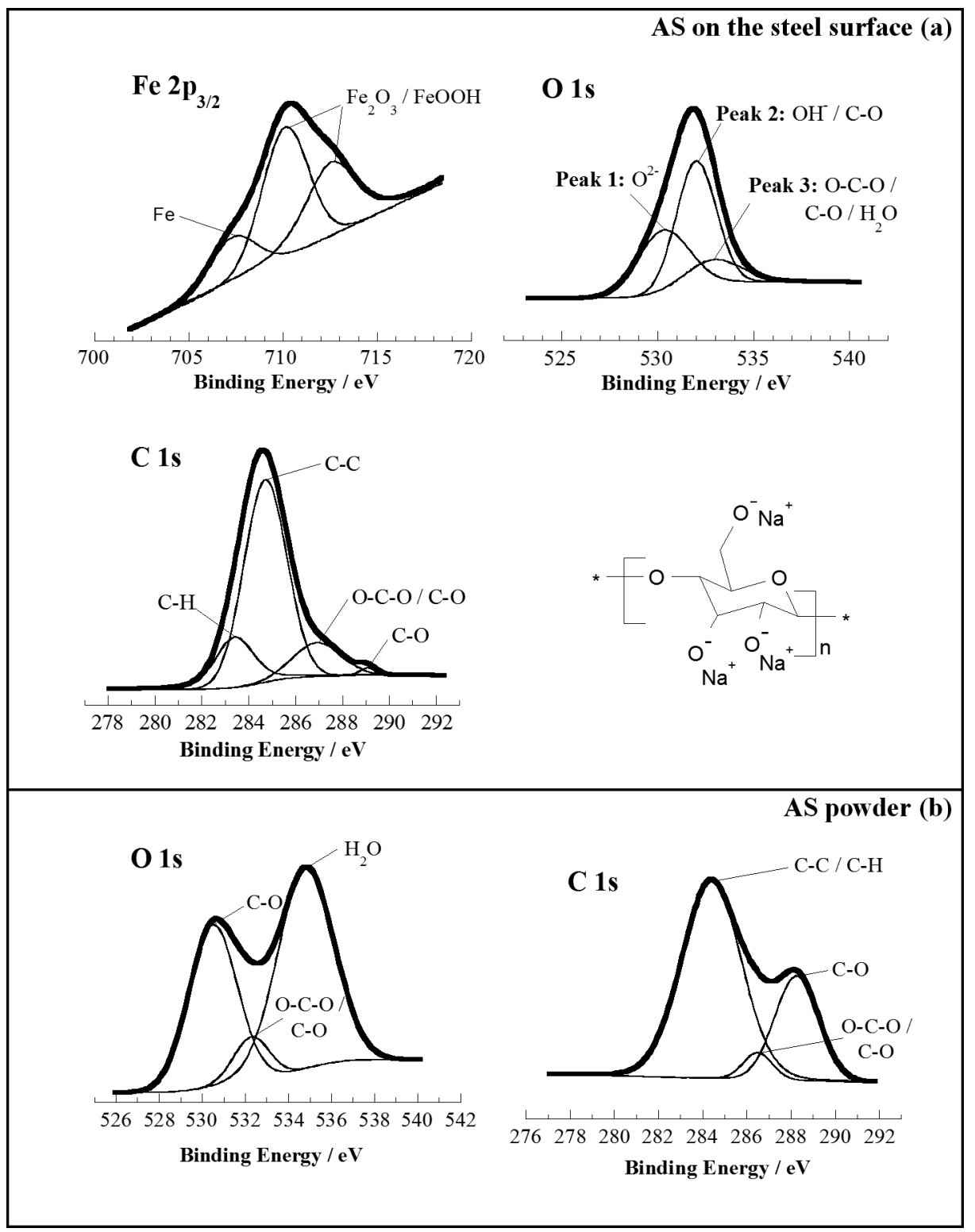

Figure 7. XPS spectra obtained for (a) the carbon steel surface after $2 \mathrm{~h}$ of immersion in the solution containing $600 \mathrm{mgL}^{-1}$ of $\mathrm{AS}$ and (b) AS powder. 
activated starch powder shown in Figure $7 \mathrm{~b}$. It should be mentioned that the hydrophilic character of the starch leads to the presence of an important water signal in the O1s spectrum of the starch powder, which is also found in the O1s spectrum of the inhibitive layer, but with a lower intensity, as expected.

By analyzing Figure 8, some differences may be appreciated when the spectra of $\mathrm{Fe} 2 \mathrm{p}_{3 / 2}, \mathrm{O} 1 \mathrm{~s}$, and $\mathrm{C} 1 \mathrm{~s}$ are compared with those shown in Figure 7. The metallic iron signal is not observed in the Fe2p spectrum of Figure 8, suggesting that the inhibitive layer formed in the presence of $\mathrm{CMS}_{0.24}$ is thicker; the three signals observed are located in the region corresponding to iron oxide/hydroxide species. In addition, there appears a peak at $533 \mathrm{eV}$ in the $\mathrm{O} 1 \mathrm{~s}$ spectrum, which corresponds to the binding energy of the carboxylate groups $\left(\mathrm{O}=\mathrm{C}-\mathrm{O}^{-}\right)$grafted to the starch molecules after the chemical modification ${ }^{49}$. In fact, the equivalent signal is observed both in the $\mathrm{C}$ 1s spectra obtained on the steel surface and from the $\mathrm{CMS}_{0.24}$ powder. As in the case of the AS, the presence of these signals reveals that $\mathrm{CMS}_{0.24}$ molecules are incorporated to the iron/hydroxide layer formed on the metal surface.

\subsection{Influence of the immersion time on the inhibitive properties of the starches}

With the purpose of monitoring the inhibitive properties of the activated and carboxymethylated starch, impedance diagrams were recorded at the corrosion potential after 24 hours of immersion in the solution containing $600 \mathrm{mgL}^{-1}$ of inhibitor (Figure 9). In the presence of AS, it may be

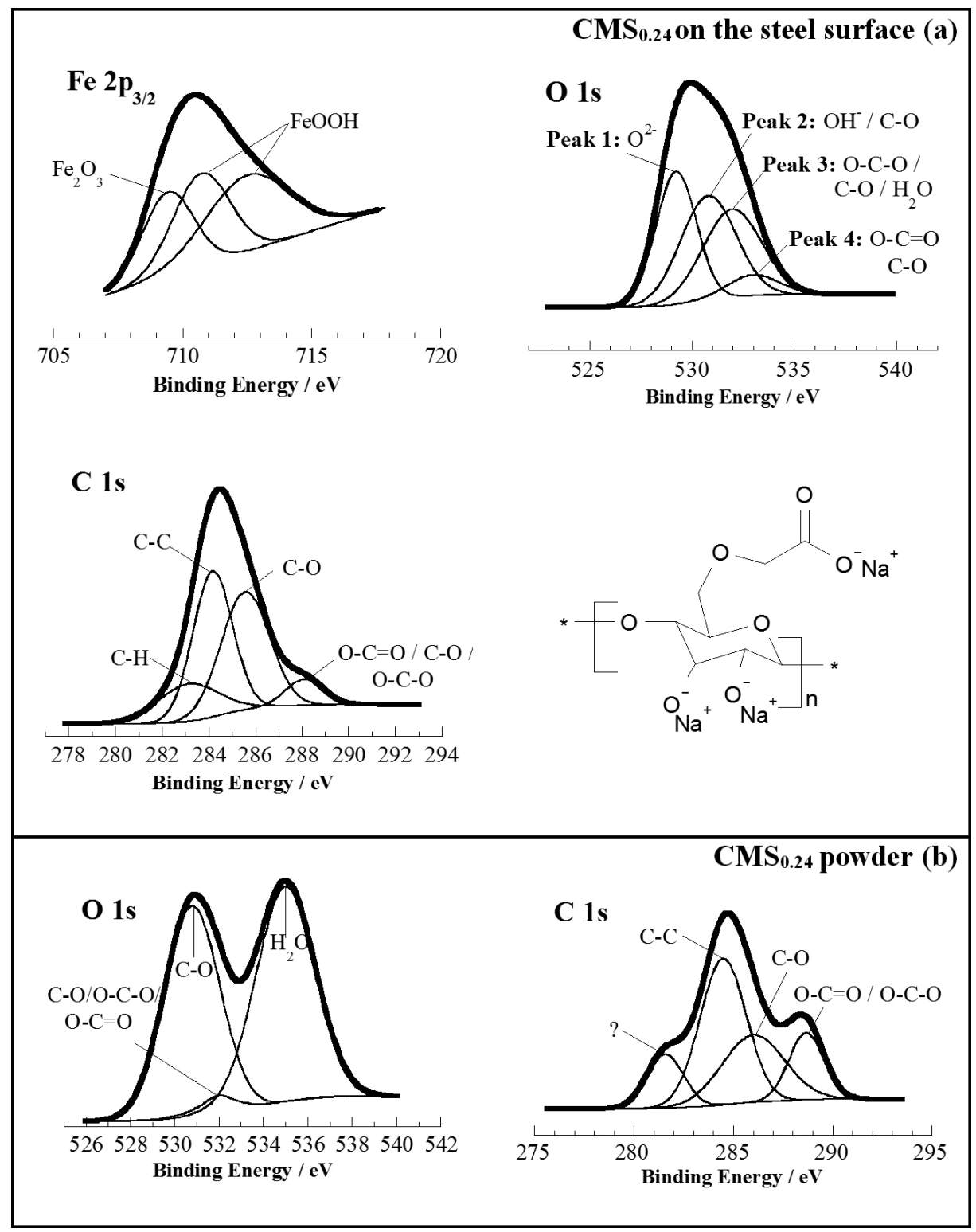

Figure 8. XPS spectra obtained for (a) the carbon steel surface after $2 \mathrm{~h}$ of immersion in the solution containing $600 \mathrm{mgL}^{-1}$ of $_{\mathrm{CMS}}$ and (b) $\mathrm{CMS}_{0.24}$ powder. 


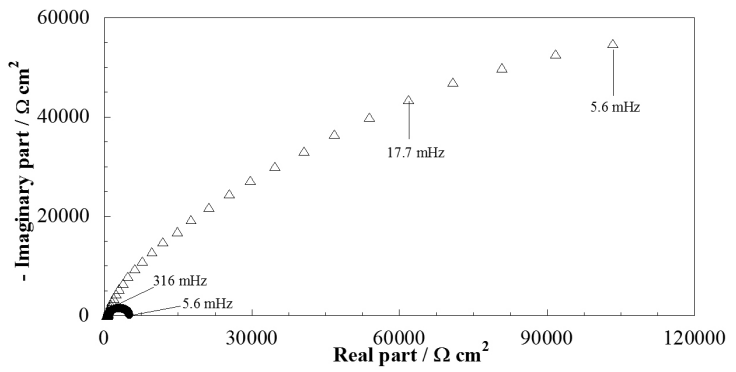

Figure 9. Electrochemical impedance diagrams obtained after $24 \mathrm{~h}$ of immersion at $E_{\text {corr }}$ in the solution containing $600 \mathrm{mgL}^{-1}$ of AS $(\Delta)$ and $\mathrm{CMS}_{0.24}(\bullet)$.

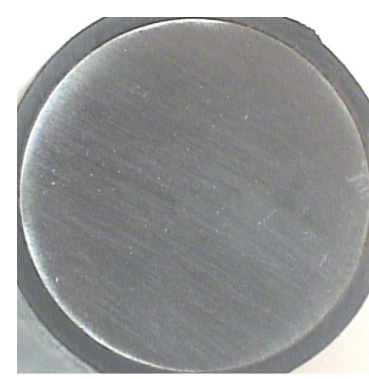

(a)

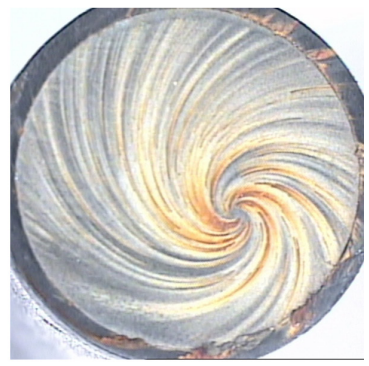

(b)
Figure 10. Pictures of the XC 35 carbon steel surfaces after $24 \mathrm{~h}$ of immersion in the solution containing $600 \mathrm{mgL}^{-1}$ of (a) AS and (b) $\mathrm{CMS}_{0.24}$. noticed that the size of the impedance diagram remains relatively constant in comparison with that obtained after two hours of immersion. Conversely, when $\mathrm{CMS}_{0.24}$ is employed, the size of the capacitive loop is significantly reduced with immersion time. These results agree with the images of the surface electrode shown in Figure 10. This result demonstrates that the $\mathrm{CMS}_{0.24}$ loses its inhibitive properties after 24 hours of immersion, whereas AS molecules maintains them. This could be explained by the higher hydrophilic character of $\mathrm{CMS}_{0.24}$, which leads to a weak chemical bond between carboxylate groups and metal surface.

In order to investigate the behavior shown by AS with the immersion time, XPS analysis were carried out on the electrode surfaces, after 24 hours of immersion in the solution containing $600 \mathrm{mg} \mathrm{L}^{-1}$ of this biopolymer (Figure 11). The spectra were similar to those of Figure 7, indicating that the AS macromolecules still remain adsorbed on the steel surface, with the only difference that the signal associated to the metal iron $(707 \mathrm{eV})$ disappeared. This result could be related to a thickening of the inhibitive film when the immersion time increases, as evidenced by AFM images published in our previous work ${ }^{32}$.

\section{Discussion}

The structural characterization of the bioinhibitors revealed that the modified cassava starches have active groups capable to interact with the metal surface: alkoxy $\left(-\mathrm{CO}^{-}\right)$groups in the presence of AS, and both alkoxy and carboxylate $\left(\mathrm{COO}^{-}\right)$groups when $\mathrm{CMS}_{0.24}$ is employed.

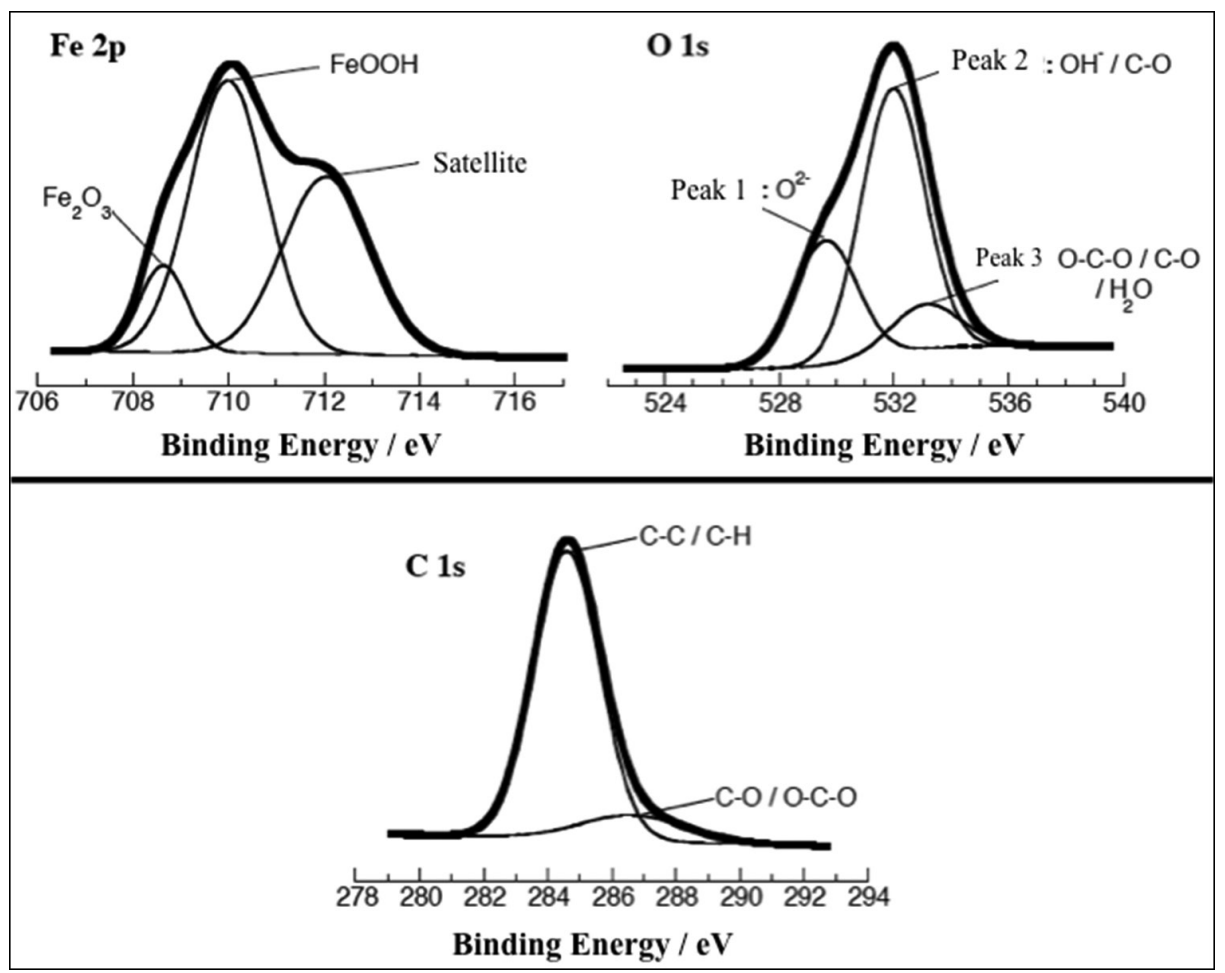

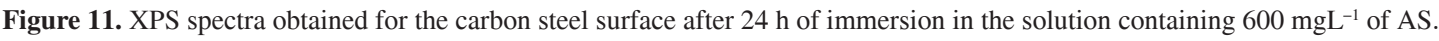


From electrochemical measurements, it was demonstrated that both macromolecules act as corrosion inhibitors of carbon steel in $200 \mathrm{mgL}^{-1}$ sodium chloride solution. It was found that the inhibitive properties increase with the concentration, independently of the modified starch used; nevertheless, impedance diagrams showed that the protective properties exhibited by AS are significantly larger and that they are kept high with the immersion time. XPS analyses demonstrated that the inhibitive film is composed by an iron oxide/hydroxide layer, in which starch molecules are incorporated. The signal at $533 \mathrm{eV}$ in the $\mathrm{O} 1 \mathrm{~s}$ regions (Figure 7a and 8a) may be attributed to the formation of a chelate between starch molecules and the oxidized metal substrate ${ }^{36,52,53}$. When AS is employed, such chelate is formed between alkoxyde groups $\left(-\mathrm{CO}^{-}\right)$and ferrous cations, while in the case of $\mathrm{CMS}_{0.24}$, the chelate would be preferentially formed between carboxylate groups and the oxidized metal substrate, due its faster accessibility determined by the greater size of the monomeric unit (see Figure 1). If the relative areas of the signals located at $533 \mathrm{eV}$ for both inhibitors are compared, it is found that a higher chelate fraction is achieved with AS. Thus, the inhibition mechanism is related to the formation of chelates between the active groups of the macromolecules and the ferrous cations, thereby sealing the pores and defects of the corrosion products layer deposited onto the metal surface, at the first stage of the electrochemical process. The higher inhibition performance achieved in the presence of AS can be explained by the stronger ionic interaction between AS and metal cations as was demonstrated by an electrostatic potential mapping of the AS and CMS monomeric units ${ }^{32}$. The relative weakness of the ionic interaction between CMS molecules and metal substrate may be also explained by resonance stabilization of the carboxylate anions ${ }^{26}$. Furthermore, $\mathrm{CMS}_{0.24}$ is more hydrophilic than $\mathrm{AS}^{22}$ and has a lower molecular weight. Both of these parameters would contribute to increase the solubility of CMS in water, establishing a competence between solution and adsorption of CMS molecules. This suggests that the reduction of the inhibitive properties of $\mathrm{CMS}_{0.24}$ with the immersion time could be attributed to desorption of the carboxymethylated starch and/or a degradation of this natural polymer.

All previous results indicate that the inhibitive film formed on the metal surface in the presence of AS is more

\section{References}

1. Frenier WW. Review of green chemistry corrosion inhibitors for aqueous systems. In: Proceedings of 9th European symposium on corrosion and scale inhibitors. In: Proceedings of the 9th European symposium on corrosion and scale inhibitors; 2000; Ferrara. Ann. Univ. Ferrara; 2000. p. 24.

2. Ismail KM. Evaluation of cysteine as environmentally friendly corrosion inhibitor for copper in neutral and acidic chloride solutions. Electrochimica Acta. 2007; 52:7811-9. http://dx.doi. org/10.1016/j.electacta.2007.02.053

3. Rahim AA, Rocca E, Steinmetz J and Kassim M.J. Inhibitive action of mangrove tannins and phosphoric acid on prerusted steel via electrochemical methods. Corrosion Science. 2008; 50(6):1546-50. http://dx.doi.org/10.1016/j. corsci.2008.02.013 stable than the film formed with $\mathrm{CMS}_{0.24}$. Moreover, with AS the inhibitive properties improve with the immersion time in contrast with the behavior shown by the $\mathrm{CMS}_{0.24}$. These results are attributed to an increased adsorption of the AS molecules on the metal surface and a densification that may be related to a retrogradation process. In fact, it has been reported that starch molecules may retrograde in the presence of water ${ }^{54}$; i.e, that the amylose fraction of the starch may crystallize.

\section{Conclusions}

From electrochemical measurements it was clearly shown that modified cassava starches, such as AS and $\mathrm{CMS}_{0.24}$, are able to inhibit carbon steel corrosion. Depending on the type of modification, they may act as mixed (AS) or anodic $\left(\mathrm{CMS}_{0.24}\right)$ inhibitors, whose protective properties increase with concentration. The impedance diagrams recorded at the corrosion potential indicated that AS is a better corrosion inhibitor because it promotes the formation of a more stable, compact, and protective film than $\mathrm{CMS}_{0.24}$. These results were explained taking into account the stronger ionic interaction with the metal surface and lower hydrophilicity. XPS analysis showed that the protective films are composed by an iron oxide/hydroxide layer, in which the starch molecules are incorporated, that blocks the active sites by means of the formation of a chelate between the alkoxyde and/or carboxylate groups present in the starches, and the oxidized metallic surface. These results, together with the low cost, biodegradability, and high availability of activated cassava starch, make of this compound a potential commercial product as green corrosion inhibitors.

\section{Acknowledgments}

We gratefully acknowledge funding provided by the Venezuelan National Fund for Research (FONACIT) and Decanato de Investigación y Desarrollo from Universidad Simón Bolívar through projects G2005000776 and GID-G02, respectively. We also would like to thank MSc. K. Contó for the preparation of the starch samples employed in this work.

4. Chetouani A, Hammouti B and Benkaddour M. Corrosion inhibition of iron in hydrochloric acid solution by jojoba oil. Pigment and Resin Technology. 2004; 33:26-31. http://dx.doi. org/10.1108/03699420410512077

5. Rauscher A, Kutsan G, Bundula R and Szailes T. StructureInhibition activity relationship of some acetylenic compounds. In: Proceedings of 9th European Symposium on Corrosion and Scale Inhibitors; 2000; Ferrara. Ann. Univ. Ferrara; 2000. p. 105.

6. Chauhan LR and Gunasekaran G. Corrosion inhibition of mild steel by plant extract in dilute $\mathrm{HCl}$ medium. Corrosion Science. 2007; 49:1143-61. http://dx.doi.org/10.1016/j. corsci.2006.08.012

7. El-Etre AY. Inhibition of C-steel corrosion in acidic solution using the aqueous extract of zallouh root. Materials Chemistry 
and Physics. 2008; 108:278-82. http://dx.doi.org/10.1016/j. matchemphys.2007.09.037

8. El-Etre AY, Abdallah M and El-Tantawy ZE. Corrosion inhibition of some metals using lawsonia extract. Corrosion Science. 2005; 47(2):385-95. http://dx.doi.org/10.1016/j. corsci.2004.06.006

9. Bouyanzer A, Hammouti B, Majidi L, Pennyroyal oil from Mentha pulegium as corrosion inhibitor for steel in $1 \mathrm{M} \mathrm{HCl}$. Materials Letters. 2006; 60:2840-3. http://dx.doi.org/10.1016/j. matlet.2006.01.103

10. Oguzie EE. Corrosion inhibition of aluminium in acidic and alkaline media by Sansevieria trifasciata extract. Corrosion Science. 2007; 49:1527-39. http://dx.doi.org/10.1016/j. corsci.2006.08.009

11. Sugama T and Dubai JE. Polyorganosiloxane-grafted potato starch coatings for protecting aluminum from corrosion. Thin Solid Films. 1996; 289:39-48. http://dx.doi.org/10.1016/S00406090(96)08814-1

12. Radojcic I, Berkovic K and Kovac S. Vorkapic-Furac J. Natural honey and black radish juice as tin corrosion inhibitors. Corrosion Science. 2008; 50:1498-504. http://dx.doi. org/10.1016/j.corsci.2008.01.013

13. Raja PB and Sethuraman MG. Natural products as corrosion inhibitor for metals in corrosive media - A review. Materials Letters. 2008; 62:113-6. http://dx.doi.org/10.1016/j. matlet.2007.04.079

14. Olusegun A, Otaige $\mathrm{J}$ and Kio O. Gossipium hirsutum L. extracts as green corrosion inhibitor for aluminum in $\mathrm{NaOH}$ solution. Corrosion Science. 2009; 51:1879-81. http://dx.doi. org/10.1016/j.corsci.2009.04.016

15. Matheswaran PandRamasamy A. A Study of Mild Steel Corrosion Using Adhatoda Vasica (AV) Extract as Inhibitor in Different Acid Medium. E-Journal of Chemistry, 2010; 7(4):1284-89. http://dx.doi.org/10.1155/2010/546360

16. Ekanem U, Umoren S, Udousor I and Udoh A. Inhibition of mild steel corrosion in $\mathrm{HCl}$ using pineapple leaves (Ananas comosus L.) extract. Journal of Materials Science. 2010; 45:5558-66. http://dx.doi.org/10.1007/s10853-010-4617-y

17. Urvija $G$ and Tak R. Inhibition of the Corrosion of Mild Steel in Acid Media by Naturally Occurring Acacia Senegal. E-Journal of Chemistry. 2010; 7(4):1220-9. http://dx.doi. org/10.1155/2010/715047

18. Lebrini M, Robert F and Roos C. Inhibition Effect of Alkaloids Extract from Annona Squamosa Plant on the Corrosion of C38 Steel in Normal Hydrochloric Acid Medium. International Journal of Electrochemical Science. 2010; 5:1698-712.

19. Solomon M, Umoren S and Udoh A. Inhibitive and adsorption behaviour of carboxymethyl cellulose on mild steel corrosion in sulphuric acid solution. Corrosion Science. 2010; 52:1317-25. http://dx.doi.org/10.1016/j.corsci.2009.11.041

20. Jie Y, Wen-ren C, Manurung RM, Ganzeveld KJ and Heeres HJ. Exploratory Studies on the Carboxymethylation of Cassava Starch in Water-miscible Organic Media. Starch/Stärke, 2004; 56:100-7. http://dx.doi.org/10.1002/ star.200300239

21. Burrell MM. Starch: the need for improved quality or quantity - an overview. Journal of Experimental Botany. 2003; 54:451-6. PMid:12508055. http://dx.doi. org/10.1093/jxb/erg049

22. Heinze T and Koschella A. Carboxymethyl ethers of cellulose and starch - a review. Macromolecular Symposia. 2005; 223:1340. http://dx.doi.org/10.1002/masy.200550502
23. Tijsen CJ, Kolk HJ, Stamhuis EJ and Beenackers AACM. An experimental study on the carboxymethylation of granular potato starch in non-aqueous media. Carbohydrate Polymers. 2001; 45:219-26. http://dx.doi.org/10.1016/S01448617(00)00243-5

24. Bhattacharyya D, Singhal R and Kulkarni P. A comparative account of conditions for synthesis of sodium carboxymethyl starch from corn and amaranth starch. Carbohydrate Polymers. 1995; 27:247-53. http://dx.doi.org/10.1016/01448617(95)00083-6

25. Heinze T, Pfeiffer K, Liebert T and Heinze U. Effective Approaches for Estimating the Functionalization Pattern of Carboxymethyl Starch of Different Origin. Starch/ Stärke 1999; 51:11-6. http://dx.doi.org/10.1002/(SICI)1521379X(199901)51:1<11::AID-STAR11>3.0.CO;2-2

26. Contó K. Sarch chemical modification by quaternary amonium salts. [Dissertation]. Caracas: Simón Bolívar University; 2008.

27. Mollega S, Barrios S, Feijoo JL, Müller AJ, Contreras J and López-Carrasquero F. In: Anales do XII Coloquio Venezolano de Polímeros; 2007; Cumaná. Cumaná; 2007. p. 99.

28. Stojanovic Z and Jeremic K. A Comparison of Some Methods for the Determination of the Degree of Substitution of Carboxymethyl Starch. Starch/Stärke. 2005; 57:79-83. http:// dx.doi.org/10.1002/star.200400342

29. Abd El Haleem S, Abd El Rehim S and Shalaby M. Anodic behaviour and pitting corrosion of plain carbon steel in $\mathrm{NaOH}$ solutions containing $\mathrm{Cl}^{-}$ions. Surface and Coatings Technology. 1986; 27:167-73. http://dx.doi.org/10.1016/02578972(86)90127-1

30. Rosliza R and Wan Nik WB. Improvement of corrosion resistance of AA6061 alloy by tapioca starch in seawater. Current Applied Physics. 2009; 10:221-29. http://dx.doi. org/10.1016/j.cap.2009.05.027

31. Bello M, Ochoa N and Balsamo V. Effect of the environmental $\mathrm{pH}$ on the corrosion bioinhibitive properties of modified cassava starches. In: Proceedins of the 69th Annual Technical Conference \& Exhibition; 2011; Boston. Boston; 2011. p. 266.

32. Bello M, Ochoa N, Balsamo V, López-Carrasquero F, Coll S, Monsalve A et al. Modified cassava starches as green corrosion inhibitors of carbon steel: An electrochemical and Morphological approach. Carbohydrate Polymers. 2010; 82:561-8. http:// dx.doi.org/10.1016/j.carbpol.2010.05.019

33. Bello M, Sancristóbal J, Ochoa N and Balsamo V. Effect of the degree of substitution of carboxymethylated cassava starch tested as green corrosion inhibitor of carbon steel. In: Proceedins of the 68th Annual Technical Conference \& Exhibition; 2010; Orlando. Orlando; 2010. p. 115.

34. Duprat M, Lafont MC, Dabosi F and Moran F. Study of the corrosion and inhibition processes of a carbon steel in a low conductivity medium by electrochemical methods. Electrochimica Acta. 1985; 30:353-65. http://dx.doi. org/10.1016/0013-4686(85)80196-1

35. Ochoa N, Moran F and Pébère N. The Synergistic Effect Between Phosphonocarboxylic Acid Salts and Fatty Amines for the Corrosion Protection of a Carbon Steel. Journal of Applied Electrochemistry. 2004; 34:487-93. http://dx.doi. org/10.1023/B:JACH.0000021702.49827.11

36. Ochoa N, Moran F, Pébère N and Tribollet B. Influence of flow on the corrosion inhibition of carbon steel by fatty amines in association with phosphonocarboxylic acid salts. Corrosion Science. 2005; 47:593-604. http://dx.doi.org/10.1016/j. corsci.2004.07.021

37. Mexal J, Fisher JT and Osteryoung J. C.P.P Oxygen availability in polyethylene glycol solutions and its implications in plant- 
water relations. Plant Physiology. 1975; 55:20-4. http://dx.doi. org/10.1104/pp.55.1.20

38. American Society for Testing and Materials. ASTM G102-89 Standard: Standard Practice for Calculation of Corrosion Rates and Related Information from Electrochemical Measurements of the American Society for testing materials. ASTM; 1989.

39. Kittipongpatana O, Sirithunyalug J and Laenger R. Preparation and physicochemical properties of sodium carboxymethyl mungbean starches. Carbohydrate Polymers. 2006; 63:105-12. http://dx.doi.org/10.1016/j.carbpol.2005.08.024

40. Hatakeyama T and Hatakeyama H. Thermal Properties of Green Polymers and Biocomposites. Dordrecht: Kluwer Academic Publishers; 2004.

41. Balsamo V, López-Carrasquero F, Laredo E, Contó K, Contreras J and Feijoo JL. Preparation and Thermal Stability of Carboxymethylstarch/Quaternary Ammonium Salts Complexes. Carbohydrate Polymers. 2011; 83(4):1680-9. http://dx.doi.org/10.1016/j.carbpol.2010.10.025

42. Orazem ME, Pébère N and Tribollet B. Enhanced Graphical Representation of Electrochemical Impedance Data. Journal of The Electrochemical Society. 2006; 153:129-36. http://dx.doi. org/10.1149/1.2168377

43. Orazem ME and Tribollet B. Electrochemical Impedance Spectroscopy., John Wiley \& Sons Inc.; 2008. chapt. 17. http:// dx.doi.org/10.1002/9780470381588

44. Asami K, Hashimoto K and Shimoraira S. X-ray photoelectron spectrum of $\mathrm{Fe}^{2+}$ state in iron oxides. Corrosion Science. 1976; 16:35-45. http://dx.doi.org/10.1016/S0010938X(76)80005-4

45. Konno H and Nagayama M. Passivity of Metals. Electrochemical Society; 1978.

46. Mathieu HJ, Bergmann E and Gras R. Traité des Matériaux: Analyse et Technologie des Surfaces. Presses Polytechniques et Universitaires Romandes; 2003. v. 4. PMid:12766544.
47. Grosvenor AP, Kobe BA, Biesinger MC and McIntyre NS. Investigation of multiplet splitting of Fe 2p XPS spectra and bonding in iron compounds. Surface and Interface Analysis. 2004; 36:1564-74. http://dx.doi.org/10.1002/sia.1984

48. Boyd RD, Verran J, Hall KE, Underhill C and Hibbert SR. The cleanability of stainless steel as determined by X-ray photoelectron spectroscopy. Applied Surface Science. 2001; 172:135-43. http://dx.doi.org/10.1016/S01694332(00)00840-0

49. Xiong H, Tang S, Tang H and Zou P. The structure and properties of a starch-based biodegradable film. Carbohydrate Polymers. 2008; 71:263-68. http://dx.doi.org/10.1016/j. carbpol.2007.05.035

50. Angellier H, Molina-Boisseau S, Belgacem MN and Dufresene A. Chemical surface modification of waxy maize starch nanocrystals. Langmuir. 2005; 21:2425-33. PMid:15752035. http://dx.doi.org/10.1021/la047530j

51. Rindlav-Westling $\AA$ and Gatenholm P. Crystallinity and Morphology in Films of Starch, Amylose and Amylopectin Blends. Biomacrom. 2003; 4:166-72. PMid:12523862. http:// dx.doi.org/10.1021/bm0256810

52. Suzuki T, Nishihara $\mathrm{H}$ and Aramaki K. The synergistic inhibition effect of octylmercaptopropionate and 8-quinolinol on the corrosion of iron in an aerated $0.5 \mathrm{M} \mathrm{Na}_{2} \mathrm{SO}_{4}$ solution. Corrosion Science. 1996; 38:1223-34. http://dx.doi. org/10.1016/0010-938X(95)00172-G

53. Bommersbach P, Alemany-Dumont C, Millet JP and Normand B. Formation and behaviour study of an environmentfriendly corrosion inhibitor by electrochemical methods. Electrochimica Acta. 2005; 51:1076-84. http://dx.doi. org/10.1016/j.electacta.2005.06.001

54. Perdomo J, Cova A, Sandoval AJ, García L, Laredo E and Müller AJ. Glass transition temperatures and water sorption isotherms of cassava starch. Carbohydrate Polymers. 2009; 76:305-13. http://dx.doi.org/10.1016/j.carbpol.2008.10.023 